\title{
Comparison of medical abortion with surgical vacuum aspiration: women's preferences and acceptability of treatment
}

\author{
R C Henshaw, S A Naji, I T Russell, A A Templeton
}

\author{
Abstract \\ Objectives-To assess women's preferences for, \\ and the acceptability of, medical abortion and \\ vacuum aspiration in the early first trimester. \\ Design-Patient centred, partially randomised \\ trial. Medical abortion was performed with mife- \\ pristone $600 \mathrm{mg}$ followed 48 hours later by gemeprost \\ $1 \mathrm{mg}$ vaginal pessary. Vacuum aspiration was \\ performed under general anaesthesia. \\ Setting-Teaching hospital in Scotland.
}

Patients-363 women undergoing legal induced abortion at less than nine weeks' gestation.

Main outcome measures-Women's preferences for method of abortion before abortion; acceptability judged two weeks after abortion by recording the method women would opt to undergo in future and by semantic differential rating technique.

Results $-73(20 \%)$ women preferred to undergo medical abortion, and $95(26 \%)$ vacuum aspiration; $195(54 \%)$ were willing to undergo either method, and were allocated at random. Both procedures were highly acceptable to women with preferences. Gestation had a definite effect on acceptability in randomised women; at less than $\mathbf{5 0}$ days there were no differences, but between 50 and 63 days vacuum aspiration was significantly more acceptable.

Conclusions-Women who wish to use a particular method should be allowed their choice, regardless of gestation. Women of 50-63 days' gestation without preferences for a particular method are likely to find vacuum aspiration more acceptable. $A$ patient centred, partially randomised trial design may be a useful tool in pragmatic research.

\section{Introduction}

In Britain, one third of all legally induced terminations of pregnancy are performed at less than nine weeks' gestation; $99 \%$ of these early abortions are achieved surgically by vacuum aspiration, usually under general anaesthesia. ${ }^{12}$ Medical abortion with mifepristone (RU 486) and a gemeprost vaginal pessary is now available, and reports suggest that it provides a safe and effective alternative to surgery in early pregnancy. ${ }^{3-6}$ However, the demand for, and the acceptability of, medical abortion in British women is largely unknown.

There is an increasing awareness among both the

Department of Obstetrics and Gynaecology, Aberdeen Maternity Hospital, Aberdeen AB9 2ZD

R C Henshaw, lecturer A A Templeton, professor of obstetrics and gynaecology

Health Services Research Unit, Department of Public Health, Aberdeen AB9 2ZD S A Naji, research fellow

I T Russell, director

Correspondence to: Dr Henshaw.

$B M F$ 1993;307:714-7 general public and the medical profession of the need to incorporate patients' preferences into medical decision making. The acceptability of any method of treatment will influence the degree to which it is used by consumers, with important implications for health care planners. ${ }^{78}$ Recognising this, Schwartz and Lellouch distinguished between "explanatory" and "pragmatic" objectives in clinical trials." Explanatory trials seek to enhance scientific knowledge by identifying the most efficacious treatment under ideal circumstances, but generalising from a rigidly controlled experiment to actual clinical practice may be difficult. ${ }^{111}$ Pragmatic trials seek to answer the clinically more relevant question, "Which treatment is most effective in normal clinical practice?", thus contributing to improved decision making. ${ }^{12}$
The trial design used in this study extends this argument by taking patients' preferences into account in the allocation of treatments. It generates two groups of women in whom motivational factors have been optimised by allowing them to choose their own treatment. At the same time it provides two groups of randomised women in whom motivational factors have been equalised, thus making it possible to investigate the true treatment effects. Comparisons of all four groups allows the independent effect of women's preferences to be examined, thus supplying information on the benefits of providing a choice. ${ }^{13}$

\section{Subjects and methods}

The sole criterion for entry to the study was eligibility to undergo both surgical vacuum aspiration and medical abortion with mifepristone and gemeprost (contraindications to medical abortion are shown in the box). Gestation was estimated with sure menstrual dates and confirmatory physical examination. When menstrual dates were unreliable (unsure dates, irregular menses, use of hormonal contraception) or there was a discrepancy on physical examination, transvaginal ultrasonography was used. In all, 373 women were invited to join the study, but three declined. We thus exceeded our target sample size of 360 , designed to yield $80 \%$ power of detecting at the $5 \%$ significance level a difference of $10 \%$ (for example, between $82 \%$ and $92 \%$ ) in the overall proportion of women finding medical or surgical abortion acceptable. ${ }^{14}$ Analysis was by intention to treat: women allocated to a method of termination were attributed to that method for the purpose of analysis, whether or not they underwent their allocated procedure.

After an abortion had been agreed under the terms of the 1967 Abortion Act, eligible women were given a standardised information sheet describing medical and surgical methods of abortion and were asked if they were willing to be allocated to a method of abortion at random. Women who agreed were assigned to a method by opening consecutive sealed opaque envelopes containing random numbers generated by computer; unknown to the study coordinator ( $\mathrm{RCH}$ ) these numbers were constrained to ensure that the numbers of women in each of the two random groups were equal after each block of 10 patients. Women who declined randomisation invariably did so because one of the alternatives seemed much more attractive; these

Contraindications to medical abortion with mifepristone and gemeprost

Pregnancy of 64 or more days' gestation

Suspected ectopic pregnancy

Chronic adrenal failure

Long term corticosteroid treatment

Haemorrhagic disorder and treatment with anticoagulants

Known allergy to mifepristone

Smokers over 35 years of age 
women were allocated to their preferred method. Eligible women were therefore allocated to one of four groups in accordance with the patient centred, partially randomised trial design proposed by Brewin and Bradley. ${ }^{13}$

Standard techniques were used to perform the abortions. Women undergoing medical abortion were asked to swallow mifepristone $600 \mathrm{mg}$ in the hospital and were admitted to the gynaecological ward 48 hours later, when gemeprost $1 \mathrm{mg}$ vaginal pessary was given. All vacuum aspirations were performed under general anaesthesia; women were admitted to the same gynaecological ward and cared for by the same nurses. Ninety per cent of surgical abortions and $99 \%$ of medical abortions were performed as day cases. Arrangements were made for all women to attend for follow up.

Seven women who had agreed to participate in the study elected to continue with their pregnancy; five were to have undergone vacuum aspiration and two medical abortion; neither of those meant to have medical abortion had taken mifepristone before withdrawing. A total of 363 women underwent abortion, and $348(96 \%)$ attended for follow up a mean (SD) of $16(4 \cdot 6)$ days later.

Women who expressed a preference for one treatment method were asked to describe "what things were important in making you decide to use this particular method." The acceptability of the procedure was assessed by self administered questionnaire at the follow up visit, in particular by responses to the closed question, "If you ever had to have another termination of pregnancy, which method would you opt for?" and by a semantic differential rating technique. This instrument uses a pair of opposite adjectives (for example, good-bad) as endpoints on a graphic Likert scale; the subject is asked to indicate her description of something by placing a mark on the scale, which is subsequently scored. When an individual describes a procedure or intervention on a set of such bipolar adjectival scales, her rating scores can be used to obtain a measure of her attitude towards the procedure; the technique has been used previously to compare women's attitudes to vacuum aspiration and medical abortion with prostaglandins alone. ${ }^{15}$ Two sets of 12 bipolar adjectives were used, scored along an evaluative dimension representing a positive or negative attitude ranging from 3 to -3 ; women were asked about the actual experience of pregnancy termination and the way they were treated by staff when they were in hospital.

\section{Results}

A total of $73(20 \%)$ women had a preference for medical abortion and $95(26 \%)$ for vacuum aspiration; $195(54 \%)$ women were willing to undergo either method, and agreed to be allocated to a method at random. A total of $99(27 \%)$ were allocated to medical abortion and $96(26 \%)$ to vacuum aspiration.

There were no significant differences among the groups in any of the physical, medical, or reproductive variables assessed (table I). Eighty four (23\%) of the study participants had undergone a previous induced abortion, but $182(50 \%)$ were pregnant for the first time. There were no significant differences in educational, marital, or socioeconomic status. However, women who expressed a preference for surgery lived a significantly greater distance from the clinic; they probably wished to avoid the extra hospital visit that may be necessary with medical abortion. This difference was not evident in women allocated to a method of abortion at random and had no influence on acceptability outcomes.

All women with a preference for a particular method expressed at least one reason for their decision; one third (49 women) gave more than one reason. Forty three $(59 \%)$ of the women who preferred medical abortion did so because they were afraid of anaesthesia or surgery. Six ( $8 \%$ ) wished to be conscious, specifically to be aware of the procedure in which they were participating. Fifteen $(21 \%)$ preferred the timescale of the procedure (surgery was seen as being "too fast"), and $15(21 \%)$ because they viewed the procedure as being less invasive and more "natural." Three women (4\%) were concerned about potential psychological effects of vacuum aspiration.

A desire to be unconscious and therefore unaware of the procedure was important to $37(39 \%)$ of the women who preferred vacuum aspiration. The timescale of surgery (medical abortion being "too slow") was important to 38 women $(40 \%)$. Fear of adverse physical effects of medical abortion was cited by 22 women $(23 \%)$, and potential psychological sequelae by one woman $(1 \%)$.

There were no significant differences in acceptability of the procedure among women allocated according to their preference; both procedures seemed to be highly acceptable, with only three women in either group (4\%) opting for a different method in the future. However, this was not true of women allocated at random. Only two women randomised to vacuum aspiration $(2 \%)$ would opt for a different method in future, suggesting that surgery was highly acceptable; but 21 women randomised to medical abortion (22\%) would opt for a different procedure in future-a highly significant difference (table II).

These findings were confirmed by the semantic differential ratings (table III). In women allocated according to their preference, on only one of the 12 bipolar adjectives (painless/painful) were the procedures rated as significantly different; vacuum aspiration was less painful. The procedures were rated as being no different on the remaining 11 bipolar adjectives. In women allocated at random, medical

TABLE II-Method of abortion that women would opt to undergo in future. Values are numbers (percentages)

\begin{tabular}{lrrrr}
\hline Group & $\begin{array}{r}\text { Opt for } \\
\text { medical } \\
\text { abortion }\end{array}$ & $\begin{array}{c}\text { Opt for } \\
\text { vacuum } \\
\text { aspiration }\end{array}$ & Undecided \\
\hline Prefer medical abortion $(n=72)$ & $68(95)$ & $3(4)$ & $1(1)$ \\
Prefer vacuum aspiration $(n=84)$ & $3(4)$ & $76(90)^{\star}$ & $5(6)$ \\
Randomised to medical abortion $(n=94)$ & $70(74)$ & $21(22)^{\star}$ & $3(3)$ \\
Randomised to vacuum aspiration $(n=95)$ & $2(2)$ & $83(87)$ & $10(11)$
\end{tabular}

Three women failed to complete the questionnaire correctly. ${ }^{\star} \mathrm{p}<0.001, \chi^{2}$ test.

TABLE I - Characteristics of 363 subjects offered medical abortion or abortion by vacuum aspiration

\begin{tabular}{|c|c|c|c|c|c|c|c|c|c|c|}
\hline Group & $\begin{array}{c}\text { Mean (SD) } \\
\text { age } \\
\text { (years) }\end{array}$ & $\begin{array}{c}\text { Mean (SD) } \\
\text { estimated } \\
\text { gestation } \\
\text { (days) }\end{array}$ & $\begin{array}{c}\text { No (\%) } \\
\text { primigravid }\end{array}$ & $\begin{array}{l}\text { No (\%) with } \\
\text { previous } \\
\text { induced } \\
\text { abortion }\end{array}$ & $\begin{array}{l}\text { No (\%) with } \\
\text { single } \\
\text { status }\end{array}$ & $\begin{array}{l}\text { No (\%) with } \\
\text { partmer } \\
\text { unaware of } \\
\text { pregnancy }\end{array}$ & $\begin{array}{l}\text { No (\%) } \\
\text { born in } \\
\text { UK }\end{array}$ & $\begin{array}{l}\text { No }(\%) \\
\text { economically } \\
\text { active }\end{array}$ & $\begin{array}{l}\text { Mean (SD) } \\
\text { age left } \\
\text { full time } \\
\text { education } \\
\text { (years) }\end{array}$ & $\begin{array}{l}\text { Mean (SD) } \\
\text { distance from } \\
\text { residence to } \\
\text { hospital } \\
\text { (miles) }\end{array}$ \\
\hline $\begin{array}{l}\text { Prefer medical abortion }(n=73) \\
\text { Prefer vacuum aspiration }(n-95) \\
\text { Randomised to medical abortion }(n=99) \\
\text { Randomised to vacuum aspiration }(n=96)\end{array}$ & $\begin{array}{l}24 \cdot 4(6 \cdot 0) \\
25 \cdot 1(6 \cdot 2) \\
24 \cdot 9(5 \cdot 5) \\
24 \cdot 7(6 \cdot 0)\end{array}$ & $\begin{array}{l}51 \cdot 7(6 \cdot 8) \\
53.5(6 \cdot 3) \\
53.3(6 \cdot 0) \\
52.7(7 \cdot 4)\end{array}$ & $\begin{array}{l}43(59) \\
42(44) \\
48(49) \\
49(51)\end{array}$ & $\begin{array}{l}14(19) \\
20(21) \\
26(26) \\
24(25)\end{array}$ & $\begin{array}{l}44(60) \\
46(48) \\
58(59) \\
58(60)\end{array}$ & $\begin{array}{l}11(15) \\
18(19) \\
24(24) \\
27(28)\end{array}$ & $\begin{array}{l}65(89) \\
87(92) \\
95(96) \\
93(97)\end{array}$ & $\begin{array}{l}51(70) \\
57(60) \\
60(61) \\
59(62)\end{array}$ & $\begin{array}{l}17 \cdot 3(2 \cdot 1) \\
16 \cdot 7(2 \cdot 0) \\
16 \cdot 8(1 \cdot 6) \\
16 \cdot 9(2 \cdot 1)\end{array}$ & $\begin{array}{l}10 \cdot 7(17 \cdot 8) \\
20 \cdot 4(28 \cdot 3)^{\star} \\
13 \cdot 4(31 \cdot 0) \\
14 \cdot 8(21 \cdot 1)\end{array}$ \\
\hline
\end{tabular}

$\star \mathrm{p}<0.05$, three group analysis of variance. 


\begin{tabular}{|c|c|c|c|c|c|c|c|c|c|c|}
\hline \multirow[b]{2}{*}{ Adjectival pair } & \multicolumn{2}{|c|}{$\begin{array}{c}\text { Prefer } \\
\text { medical abortion }\end{array}$} & \multicolumn{2}{|c|}{$\begin{array}{c}\text { Prefer } \\
\text { vacuum aspiration }\end{array}$} & \multirow{2}{*}{$\begin{array}{c}\text { Difference in } \\
\text { means } \\
\text { (95\% confidence } \\
\text { interval) }\end{array}$} & \multicolumn{2}{|c|}{$\begin{array}{l}\text { Randomised to } \\
\text { medical abortion }\end{array}$} & \multicolumn{2}{|c|}{$\begin{array}{l}\text { Randomised to } \\
\text { vacuum aspiration }\end{array}$} & \multirow{2}{*}{$\begin{array}{c}\text { Difference in } \\
\text { means } \\
\text { (95\% confidence } \\
\text { interval) }\end{array}$} \\
\hline & No & Mean (SD) & No & Mean (SD) & & No & Mean (SD) & No & Mean (SD) & \\
\hline $\begin{array}{l}\text { Painless-painful } \\
\text { Happy-sad } \\
\text { Good-bad } \\
\text { Pleasant-unpleasant } \\
\text { Positive-negative } \\
\text { Safe-dangerous } \\
\text { Attractive-unattractive } \\
\text { Mild-harsh } \\
\text { Agreeable-disagreeable } \\
\text { Active-passive } \\
\text { Easy-hard } \\
\text { Fast-slow }\end{array}$ & $\begin{array}{l}73 \\
73 \\
73 \\
73 \\
69 \\
73 \\
73 \\
72 \\
73 \\
72 \\
73 \\
73\end{array}$ & $\begin{array}{r}-1.40(1.67) \\
-0.79(1.77) \\
-0.12(1.73) \\
-1.34(1.57) \\
0.55(1.74) \\
1.44(1.45) \\
-1.03(1.55) \\
-0.22(1.53) \\
0.15(1.84) \\
0.11(1.41) \\
-0.49(1.67) \\
0.58(1.79)\end{array}$ & $\begin{array}{l}85 \\
85 \\
85 \\
85 \\
84 \\
85 \\
84 \\
85 \\
85 \\
83 \\
85 \\
85\end{array}$ & $\begin{array}{r}0.08(1.92) \\
-0.62(1.91) \\
-0.01(1.73) \\
-0.86(1.60) \\
0.50(1.75) \\
1.41(1.46) \\
-0.76(1.29) \\
0.24(1.60) \\
0.22(1.82) \\
0.43(1.28) \\
-0.66(1.85) \\
1.08(1.52)\end{array}$ & $\begin{array}{l}1.48(0.91 \text { to } 2.05)^{\star} \\
0.17(-0.41 \text { to } 0.75) \\
0.11(-0.43 \text { to } 0.66) \\
0.48(-0.02 \text { to } 0.98) \\
0.05(-0.51 \text { to } 0.61) \\
0.03(-0.43 \text { to } 0.49) \\
0.27(-0.18 \text { to } 0.72) \\
0.46(-0.04 \text { to } 0.96) \\
0.07(-0.50 \text { to } 0.65) \\
0.32(-0.11 \text { to } 0.75) \\
0.17(-0.39 \text { to } 0.73) \\
0.50(-0.02 \text { to } 1.02)\end{array}$ & $\begin{array}{l}94 \\
94 \\
94 \\
94 \\
93 \\
93 \\
94 \\
93 \\
94 \\
93 \\
94 \\
94\end{array}$ & $\begin{array}{r}r-1.26(1.84) \\
-1.12(1.58) \\
-0.27(1.58) \\
-1.50(1.58) \\
0.32(1.70) \\
1.38(1.57) \\
-1.17(1.64) \\
-0.26(1.63) \\
-0.04(1.83) \\
0.18(1.28) \\
-0.63(1.96) \\
0.64(1.87)\end{array}$ & $\begin{array}{l}95 \\
95 \\
95 \\
94 \\
95 \\
95 \\
94 \\
95 \\
95 \\
95 \\
95 \\
95\end{array}$ & $\begin{array}{r}0.20(1.85) \\
-0.54(1.88) \\
0.26(1.70) \\
-0.68(1.58) \\
0.66(1.72) \\
1.62(1.32) \\
-0.80(1.46) \\
0.51(1.36) \\
0.40(1.56) \\
0.53(1.34) \\
-0.18(1.80) \\
1.19(1.37)\end{array}$ & $\begin{array}{l}1.46(0.93 \text { to } 1.99)^{\star} \\
0.58(0.08 \text { to } 1.08)^{\star} \\
0.53(0.06 \text { to } 1.00)^{\star} \\
0.82(0.37 \text { to } 1.27)^{\star} \\
0.34(-0.15 \text { to } 0.83) \\
0.24(-0.18 \text { to } 0.66) \\
0.37(-0.08 \text { to } 0.82) \\
0.77(0.34 \text { to } 1.20)^{\star} \\
0.44(-0.05 \text { to } 0.93) \\
0.35(-0.03 \text { to } 0.73) \\
0.45(-0.09 \text { to } 0.99) \\
0.55(0.08 \text { to } 1.02)^{\star}\end{array}$ \\
\hline
\end{tabular}

abortion was rated significantly lower on six of the bipolar adjectives.

In women allocated at random to medical abortion the sole predictor of acceptability before the abortion was estimated gestation: 20 of the 21 women (95\%) who found medical abortion unacceptable underwent the procedure at 50 or more days' gestation (table IV). At gestations less than this there was no difference in acceptability between women allocated at random to medical abortion or vacuum aspiration. Another factor correlated with acceptability in this group was the degree of pain experienced during the procedure, assessed using items from the McGill pain questionnaire. ${ }^{16}$ Thus the longer the gestation, the more painful the medical abortion and the less acceptable the procedure. However, women in the two medical groups did not differ in pain rating scores for the procedure, suggesting that preferences may be more important in predicting acceptability than adverse physical effects.

Women who have experienced both procedures form a subgroup that may be better able to judge outcomes such as acceptability. Eighty four $(23 \%)$ of our subjects had had a previous legal abortion; five of these had been performed by medical abortion (the procedure has been available in clinical trials for over five years), 69 surgically, and 10 by extra-amniotic prostaglandin administration in the second trimester. The previous method of termination had no influence on preference for abortion method; in all, 41 women ( $11 \%$ of the study sample) underwent a procedure that was different from their previous experience. When

TABLE IV-Acceptability of procedure and estimated gestation in 94 women allocated at random to medical abortion

\begin{tabular}{lrccc}
\hline $\begin{array}{l}\text { Gestation } \\
\text { (days) }\end{array}$ & No & $\begin{array}{c}\text { No (\%) opting for } \\
\text { medical abortion } \\
\text { in future }\end{array}$ & $\begin{array}{c}\text { No (\%) opting for } \\
\text { vacuum aspiration } \\
\text { in future }\end{array}$ & $\begin{array}{c}\text { No (\%) } \\
\text { undecided }\end{array}$ \\
\hline 542 & 6 & $6(100)$ & 0 & 0 \\
$43-49$ & 20 & $18(90)$ & $1(5)$ & $1(5)$ \\
$50-56$ & 39 & $27(69)$ & $12(31)$ & 0 \\
$57-63$ & 29 & $19(66)$ & $8(28)$ & $2(7)$ \\
\hline
\end{tabular}

these women were asked which method they would opt for in the future, the results were the same as in the sample as a whole: 15 of the 16 women $(94 \%)$ who were allocated to a method by preference would opt for that method again, and $17(74 \%)$ of the 23 women who had undergone vacuum aspiration in the past, and were on this occasion allocated at random to medical abortion, would opt for medical abortion again.

The quality of nursing care that the women received while inpatients could have had a profound impact on their perceptions of the two procedures. Treatment by staff was rated as positive by all groups on 11 of the 12 bipolar adjectives used in the semantic differential technique (table V). Women allocated at random showed no significant differences between vacuum aspiration and medical abortion in rating scores, so treatment by staff could not explain the differences in acceptability of the procedure. Women allocated by preference, however, rated treatment by staff significantly higher on four of the bipolar adjectival scores after medical abortion. The same staff cared for all women, regardless of the method of abortion or treatment allocation.

\section{Discussion}

Earlier studies of first trimester abortion with prostaglandins alone found that a non-surgical method to end pregnancy was aceptable to over two thirds of participants. ${ }^{17}$ In France about a fifth of women seeking termination opt for medical abortion, which has been available since $1988 .{ }^{4}$ However, demand may be much higher; a survey of 481 French women undergoing induced abortion at less than 50 days' amenorrhoea found that $62 \%$ would choose medical abortion and $32 \%$ vacuum aspiration. ${ }^{18}$ Hill et al offered 165 British women the choice of medical abortion, of whom 105 (64\%) agreed; the rest preferred vacuum aspiration, for convenience and because they wished general anaesthesia. ${ }^{19}$ When asked seven days later which method they would opt for in the future, only $9 \%$ stated they would use a different method. Smaller studies using similar criteria report that

TABLE V - Semantic differential rating scores for treatment by hospital staff

\begin{tabular}{|c|c|c|c|c|c|c|c|c|c|c|}
\hline \multirow[b]{2}{*}{ Adjectival pair } & \multicolumn{2}{|c|}{$\begin{array}{c}\text { Prefer } \\
\text { medical abortion }\end{array}$} & \multicolumn{2}{|c|}{$\begin{array}{c}\text { Prefer } \\
\text { vacuum aspiration } \\
\end{array}$} & \multirow{2}{*}{$\begin{array}{c}\text { Difference in } \\
\text { means } \\
\text { (95\% confidence } \\
\text { interval) }\end{array}$} & \multicolumn{2}{|c|}{$\begin{array}{c}\text { Randomised to } \\
\text { medical abortion }\end{array}$} & \multicolumn{2}{|c|}{$\begin{array}{l}\text { Randomised to } \\
\text { vacuum aspiration }\end{array}$} & \multirow{2}{*}{$\begin{array}{c}\text { Difference in } \\
\text { means } \\
\text { (95\% confidence } \\
\text { interval) } \\
\end{array}$} \\
\hline & No & Mean (SD) & No & Mean (SD) & & No & Mean (SD) & No & Mean (SD) & \\
\hline $\begin{array}{l}\text { Good-bad } \\
\text { Interested-uninterested } \\
\text { Relaxed-stressed } \\
\text { Sympathetic-unsympathetic } \\
\text { Agreeable-disagreeable } \\
\text { Warm-cold } \\
\text { Pleasant-unpleasant } \\
\text { Involved-uninvolved } \\
\text { Kind-unkind } \\
\text { Soft-hard } \\
\text { Gentle-harsh } \\
\text { Fast-slow }\end{array}$ & $\begin{array}{l}73 \\
73 \\
73 \\
73 \\
73 \\
73 \\
73 \\
73 \\
73 \\
73 \\
73 \\
73\end{array}$ & $\begin{array}{l}2.41(1.13) \\
1.56(1.72) \\
2.14(1.15) \\
1.81(1.49) \\
1.84(1.36) \\
1.84(1.45) \\
2.21(1.27) \\
1.18(1.82) \\
2.21(1.14) \\
1.64(1.24) \\
2.00(1.26) \\
-1.00(1.65)\end{array}$ & $\begin{array}{l}84 \\
84 \\
84 \\
84 \\
84 \\
84 \\
84 \\
84 \\
84 \\
84 \\
84 \\
84\end{array}$ & $\begin{array}{r}2.27(1.15) \\
1.19(1.64) \\
1.65(1.48) \\
1.33(1.52) \\
1.41(1.38) \\
1.58(1.41) \\
1.88(1.40) \\
0.93(1.63) \\
2.00(1.18) \\
1.11(1.43) \\
1.54(1.33) \\
-1.17(1.57)\end{array}$ & $\begin{array}{l}0.14(-0.22 \text { to } 0.50) \\
0.37(-0.16 \text { to } 0.90) \\
0.49(0.07 \text { to } 0.91)^{\star} \\
0.48(0.004 \text { to } 0.96)^{\star} \\
0.43(-0.003 \text { to } 0.86) \\
0.26(-0.19 \text { to } 0.71) \\
0.33(-0.09 \text { to } 0.75) \\
0.25(-0.29 \text { to } 0.79) \\
0.21(-0.16 \text { to } 0.58) \\
0.53(0.11 \text { to } 0.96)^{\star} \\
0.46(0.05 \text { to } 0.87)^{\star} \\
0.17(-0.34 \text { to } 0.68)\end{array}$ & $\begin{array}{l}94 \\
93 \\
94 \\
94 \\
94 \\
94 \\
94 \\
94 \\
94 \\
94 \\
94 \\
94\end{array}$ & $\begin{array}{r}2.47(0.81) \\
1.70(1.39) \\
1.97(1.18) \\
1.73(1.29) \\
1.60(1.24) \\
1.80(1.14) \\
2.15(1.03) \\
1.31(1.61) \\
2.20(0.95) \\
1.45(1.21) \\
1.86(1.05) \\
-1.10(1.37)\end{array}$ & $\begin{array}{l}94 \\
93 \\
94 \\
94 \\
94 \\
94 \\
94 \\
94 \\
94 \\
94 \\
94 \\
94\end{array}$ & $\begin{array}{r}2.32(1.03) \\
1.49(1.36) \\
1.84(1.25) \\
1.50(1.35) \\
1.56(1.29) \\
1.71(1.30) \\
1.94(1.20) \\
0.94(1.64) \\
1.94(1.14) \\
1.21(1.24) \\
1.64(1.14) \\
-1.11(1.44)\end{array}$ & $\begin{array}{l}0.15(-0.12 \text { to } 0.42) \\
0.21(-0.19 \text { to } 0.61) \\
0.13(-0.22 \text { to } 0.48) \\
0.23(-0.15 \text { to } 0.61) \\
0.04(-0.32 \text { to } 0.40) \\
0.09(-0.26 \text { to } 0.44) \\
0.21(-0.11 \text { to } 0.53) \\
0.37(-0.10 \text { to } 0.84) \\
0.26(-0.04 \text { to } 0.56) \\
0.24(-0.11 \text { to } 0.59) \\
0.22(-0.10 \text { to } 0.54) \\
0.01(-0.39 \text { to } 0.41)\end{array}$ \\
\hline
\end{tabular}

${ }^{*} \mathrm{p}<0.05$ 


\section{Clinical implications}

- Medical abortion, using mifepristone and gemeprost, is a safe and effective alternative to surgical vacuum aspiration

- Up to a third of the 200000 induced abortions performed in Britain each year could be undertaken medically

- In this study $20 \%$ of women preferred to use medical abortion and $26 \%$ vacuum aspiration; the remainder were willing to use either method

- Women who prefer to use a particular method should be allowed their choice if acceptability is to be maximised

- Women who are unsure which method to use are likely to find vacuum aspiration more acceptable at gestations of over 50 days' amenorrhoea

$75-96 \%$ of women find medical abortion acceptable, with the corresponding figures for vacuum aspiration ranging from $96 \%$ to $100 \% .{ }^{20} 21$

This study suggests that $20 \%$ of British women prefer medical abortion and that a further $54 \%$ would be willing to use the method. That $26 \%$ of women would not contemplate medical abortion shows the importance of providing choice. Travelling distance was the only statistically significant characteristic which identified women with a preference for a method of abortion.

Both medical abortion and vacuum aspiration seem to be highly acceptable in women allocated according to preference. However, women without a preference, when allocated at random, found vacuum aspiration significantly more acceptable, especially at longer gestations; even so, medical abortion was acceptable to nearly three quarters of women.

This information is useful to clinicians who are required to give practical advice to women applying to have an abortion. Women who prefer a method of abortion should be allowed their choice, regardless of length of gestation. Women presenting very early (less than 50 days' ammenorrhoea) may be reassured that they are likely to find the procedures equally acceptable; medical abortion is at its most effective at shorter gestations. ${ }^{6}$ Women of 50-63 days' gestation who are not sure which method to use may be advised that vacuum aspiration is likely to be more acceptable.

A simple randomised (or entirely pragmatic) trial would not have yielded these results. Hence, the patient centred, partially randomised trial design advocated by Brewin and Bradley may be a useful tool in pragmatic research in populations characterised by an unwillingness to comply with all treatments under investigation. ${ }^{22}$

Nearly a quarter of the women recruited into this study had had a previous induced abortion. The follow up recommended after medical abortion may provide an excellent opportunity to reinforce counselling about regular and emergency contraception.

The Health Services Research Unit is funded by the Chief Scientist Office of the Scottish Office Home and Health Department. The opinions expressed in this communication are those of the authors.

1 Botting B. Trends in abortion. Pop Trends 1991;64:19-29.

2 Joint Study of the Royal College of General Practitioners and the Royal College of Obstetricians and Gynaecologists. Induced abortion operations and their early sequelae. $\{$ R Coll Gen Pract 1985;35:175-80.

3 Castadot RG. Pregnancy termination: techniques, risks, and complications and their management. Fertil Steril 1986;45:5-17.

4 Heard M, Guillebaud J. Medical abortion. BMF 1992;304:195-6.

5 Ulmann A, Silvestre L, Chemama L, Rezvani Y, Renault M, Aguillaume C, et al. Medical abortion of early pregnancy with mifepristone (RU 486) followed by a prostaglandin analogue. Acta Obstet Gynecol Scand 1992;71: 278-83.

6 UK Multicentre Trial. The efficacy and tolerance of mifepristone and prostaglandin in first trimester termination of pregnancy. $\mathrm{Br} \mathcal{f}$ Obstet Gynaecol 1990;97:480-6.

7 Marshall JF. Acceptability of fertility regulating methods: designing technology to fit people. Prev Med 1977;6:65-73.

$8 \mathrm{McNeil}$ BJ, Pauker SG, Sox HC, Tversky A. On the elicitation of preferences for alternative therapies. N Engl f Med 1982;306:1259-62.

9 Schwart D, Lellouch J. Explanatory and pragmatic attitudes in clinical trials. fChron Dis 1967;20:637-48.

10 Charlson ME, Horwitz RI. Applying results of randomised trials to clinica practice: impact of losses before randomisation. $B M \Im$ 1984;289:1281-4.

11 Dudley HAF. The controlled clinical trial and the advance of reliable knowledge: an outsider looks in. BMF 1983;287:957-60.

12 Russell IT, Wilson BJ. Audit: the third clinical science? Quality in Health Care 1992;1:51-5.

13 Brewin CR. Bradley C. Patient preferences and randomised clinical trials. BMF 1989;299:313-5.

14 Casagrande JT, Pike MC, Smith PG. The power function of the "exact" test for comparing two binomial distributions. Appl Stat 1982;27:176-80.

15 Rosen AS, Nystedt L, Bygdeman M, Lundstrom V. Acceptability of a non-surgical method to terminate very early pregnancy in comparison to vaccum aspiration. Contraception 1979;19:107-17.

16 Melzack R. The McGill pain questionnaire: major properties and scoring methods. Pain 1975;1:277-99.

17 Rosen AS, von Knorring K, Bygdeman M, Christensen NJ. Randomised comparison of prostaglandin treatment in hospital or at home with vacuum aspiration for termination of early pregnancy. Contraception 1984;29:423-35.

18 Bachelot A, Cludy L, Spira A. Conditions for choosing between drug induced and surgical abortions. Contraception 1992;45:547-59.

19 Hill NCW, Ferguson J, MacKenzie IZ. The efficacy of oral mifepristone (RU 38,486) with a prostaglandin El analog vaginal pessary for the termination of early pregnancy: complications and patient acceptability. $\mathbf{A m}$ termination of early pregnancy:

20 Urquhart DR, Templeton AA. Psychiatric morbidity and acceptability following medical and surgical methods of induced abortion. $\mathrm{Br} f$ Obstet Gynaecol 1991:98:396-9.

21 Tang GWK. A pilot study of acceptability of RU486 and ONO 802 in a Chinese population. Contraception 1991;44:523-32.

22 Harvey I, West R, Newcombe R. Patient preferences and randomised clinical trials. BMF 1989;299:684-5.

(Accepted 13 Fuly 1993)

Clinical features, risk factors, and referral delay in British patients of Indian and European origin with angina matched for age and extent of coronary atheroma

\section{Naeem Shaukat, D P de Bono, J K Cruickshank}

Correspondence to:

Professor D P de Bono, Department of Cardiology, University of Leicester, Leicester LE3 9QP.

$B M \mathcal{F}$ 1993;307:717-8
Coronary artery disease is disproportionately prevalent in the United Kingdom in people originating from the Indian subcontinent ${ }^{12}$ and there are apparent differences in the risk factor profile. ${ }^{34} \mathrm{We}$ have compared the clinical features and risk factors in patients of Indian origin who have had coronary angiography for sus- pected angina with those of white patients with angina studied in the same clinic and matched for age and extent of coronary disease.

\section{Patients, methods, and results}

Coronary arteriograms of 154 consecutive patients of Indian origin studied at a regional cardiothoracic centre over two years were classified as normal (no stenosis greater than $50 \%$ in any vessel) or as showing single vessel disease (stenosis greater than $70 \%$ in only one coronary artery) or multivessel disease (stenosis greater than $70 \%$ in two or more coronary arteries). Thirty patients were chosen at random from each group. There were 51 Gujerati Hindus, 18 Punjabi Muslims, 14 Punjabi Sikhs, four Punjabi Hindus, and three Gujerati Muslims. Seventy (78\%) were male. All were first generation immigrants. Ninety European 